\title{
PENGARUH TEKHNIK "SPEAKING RANDOM CLUB" TERHADAP KEMAMPUAN BERBICARA PADA MAHASISWA PROGRAM STUDI TATA HIDANGAN DI AKADEMI KOMUNITAS MAPINDO PADA TAHUN AKADEMIK 2016/2017
}

\author{
Nirmala Tari ${ }^{1}$, Ni Putu Dianita Safitri ${ }^{2}$ \\ Akademi Komunitas Manajemen Perhotelan Indonesia \\ Badung, Indonesia \\ nirmalatari23@yahoo.com ${ }^{1}$, tri18 nata@yahoo.com ${ }^{2}$
}

\begin{abstract}
Abstrak
Penelitian ini bertujuan untuk meneliti apakah ada pengaruh yang berarti pada kemampuan mahasiswa dalam berbicara dengan menggunakan tekhnik Speaking Random Club. Yang menjadi populasi dalam penelitian ini adalah mahasiswa Program Studi Program Studi Tata Hidangan di Akademi Komunitas MAPINDO. Penelitian ini menggunakan hipotesis nol; yang berarti tidak ada perbedaan yang berarti diantara dua grup mahasiswa yang diajar dengan menggunakan tekhnik Speaking Random Club dan tekhnik lama. Untuk mencapai tujuan penelitian ini, Post-Test Only Control Group digunakan sebagai metode penelitian ini. Dua kelas dipilih secara acak sebagai sampel. Sistem undian diberikan, dan hasilnya menunjukan bahwa kelas TH A sebagai grup experimental dan kelas TH B sebagai grup kontrol. Setelah tekhnik diaplikasikan, tes akhir kemudian diberikan untuk menemukan pengaruh tekhnik. Data yang didapatkan dari tes akhir dianalisa dengan menggunakan perhitungan deskriptif dan inferential. Pada perhitungan deskriptif, telah didapat bahwa rata-rata grup experimental adalah 85.16 sedangkan rata-rata grup kontrol adalah 70.93 , ini berarti bahwa grup experimental memiliki kemampuan yang lebih baik daripada grup kontrol. Pada perhitungan inferential, perbedaan mahasiswa yang diajar dengan tekhnik Speaking Random Club dan tekhnik lama dibuktikan dengan tingkat significant 5 persen (0.05) dengan tobserved(15.46) lebih tinggi daripada tcritical value(1.96); ini berarti bahwa hipotesis nol ditolak. Berdasarkan penemuan di atas, dapat disimpulkan bahwa Ho (Null Hypothesis) ditolak dan $\mathrm{Ha}$ (Alternative Hypothesis) diterima. Ini artinya mahasiswa yang diajar dengan tekhnik Speaking Random Club lebih baik daripada mahasiswa yang diajar dengan tekhnik lama.
\end{abstract}

Kata kunci : Kemampuan berbicara, Speaking Random Club 


\section{PENDAHULUAN}

Pariwisata merupakan salah satu aspek kehidupan yang sangat berkembang di Bali. Banyak wisatawan baik lokal maupun interlokal berkunjung ke Bali guna menikmati keindahan wisata di Bali. Hal ini menyebabkan banyak hotel, restoran dan vila ataupun resort membutuhkan tenaga lulusan yang kompeten dibidang pariwisata.

Pekerjaan dibidang pariwisata tentunya mengutamakan kemampuan berkomunikasi baik secara langsung maupun tidak langsung. Dalam hal ini kemampuan berbicara menjadi salah satu hal terpenting untuk kelancaran berkomunikasi dengan para wisatawan terutama wisatawan mancanegara. Menurut Cutting (2000) berbicara adalah alat komunikasi yang dapat digunakan untuk mengetahui kepribadian, sikap seseorang dan memudahkan menyampaikan pendapat dan gagasan secara efisien. Kemampuan berbahasa Inggris pun menjadi tolak ukur dalam berkomunikasi dengan wisatawan mancanegara.

Berdasarkan observasi awal yang telah dilakukan terhadap mahasiswa Program Studi Program Studi Tata Hidangan di Akademi Komunitas MAPINDO, penulis menemukan masalah dalam kemampuan berbicara bahasa Inggris. Kemampuan berbicara merupakan keahlian dalam menyampaikan maksud dan gagasan secara langsung (Dewi, 2006:1).

$$
\text { Setelah diadakan observasi, }
$$

ternyata mahasiswa Program Studi Tata Hidangan belum dapat berkomunikasi dalam bahasa Inggris secara lancar dikarenakan beberapa sebab diantaranya; kurangnya rasa percaya diri, kurangnya kosa kata yang dimiliki, dan jarangnya kesempatan praktik berbicara di dalam kelas dengan menggunakan bahasa Inggris. Sehingga banyak dari mereka menghadapi kendala dalam tes wawancara menjelang pelaksanaan praktik kerja industri atau melamar pekerjaan.

Dari permasalahan yang telah dipaparkan sebelumnya, maka peneliti mengadakan penelitian dengan menerapkan salah satu tekhnik dalam berbicara guna membuktikan apakah tekhnik yang diterapkan dalam pengajaran memiliki pengaruh terhadap kemampuan berbicara mereka atau tidak. Jika ternyata hasil dari penelitian tersebut menyatakan tekhnik yang diterapkan berpengaruh dan mampu memperbaiki kemampuan berbicara pada mahasiswa Program Studi Tata Hidangan, maka selanjutnya akan diperlakukan untuk selanjutnya.

Tekhnik yang akan digunakan dalam penelitian ini adalah "Speaking Random Club". "Speaking Random Club" adalah tekhnik yang diterapkan oleh dosen pengajar Bahasa Inggris Profesi pada mahasiswa Program Studi Tata Hidangan. Dosen pengampu mata kuliah ini membagi mahasiswa menjadi beberapa kelompok yang terdiri dari empat atau 5 orang dimana anggota pada masing-masing kelompok dipilih secara acak oleh dosen. Dosen akan menetapkan beberapa mahasiswa yang memiliki kemampuan lebih dalam bahasa inggris sebagai ketua kelompok dan anggotanya dipilih secara acak dengan menggunakan lotre. Hal ini dimaksudkan agar ketua kelompok mampu memimpin anggotanya sehingga mereka dapat lebih aktif berkomunikasi.

"Speaking Random Club" pernah digunakan oleh seorang dosen di Sydney University yang bernama Flynn (2007). Flynn menerapkan kelompok belajar dalam kelas debat. la membagi mahasiswanya menjadi beberapa kelompok yang dipilih secara acak. Douglas (2007) juga menerapkan tekhnik serupa dalam debat. "Speaking Random Club" merupakan tekhnik yang cukup menarik untuk dikembangkan dalam pengajaran bahasa Inggris, karena mampu mengasah kemampuan bersosialisasi dengan sesama teman (Hammer, 1984).

Tujuan dari penelitian ini adalah membuktikan apakah tekhnik "Speaking Random Club" dapat memberikan pengaruh yang signifikan terhadap kemampuan berbicara dalam menggunakan bahasa Inggris sebagai bahasa Internasional. Adapun manfaat yang dapat dirasakan oleh peneliti-peneliti lainnya adalah dapat digunakan sebagai daftar pustaka atau bahan kajian untuk penelitian selanjutnya. Manfaat lainnya juga dapat dirasakan secara langsung oleh mahasiswa dimana mereka dapat meningkatkan kemampuan 
berbicara dalam bahasa Inggris dengan rasa percaya diri yang lebih baik.

\section{METODE PENELITIAN}

Penelitian ini dilakukan di Akademi Komunitas MAPINDO selama kurang lebih 3 bulan. Sampel penelitian ini adalah mahasiswa Program Studi Tata Hidangan A dan Program Studi Tata Hidangan B pada tahun akademik 2016/2017 yang dipilih dengan menggunakan cluster random sampling. Desain penelitian ini menggunakan posttests only control group design.

Tabel 3.3.1 Research Design of Posttest Only Control Group Design

\begin{tabular}{|c|c|c|c|}
\hline \multirow{4}{*}{$\begin{array}{c}\text { Dua } \\
\text { kelas } \\
\text { dari } \\
\text { beberapa } \\
\text { kelas } \\
\text { yang } \\
\text { dipilih } \\
\text { secara } \\
\text { acak }\end{array}$} & $\mathrm{R}$ & $\mathrm{X} 1$ & 0 \\
\hline & 1 Kelas & $\begin{array}{c}\text { Mengguna } \\
\text { kan teknik } \\
\text { Random } \\
\text { Club } \\
\text { dalam } \\
\text { kelas } \\
\text { speaking }\end{array}$ & $\begin{array}{l}\text { Variabe } \\
\text { I } \\
\text { depend } \\
\text { en }\end{array}$ \\
\hline & $\mathrm{R}$ & $\mathrm{X} 2$ & 0 \\
\hline & 1 Kelas & $\begin{array}{c}\text { Tanpa } \\
\text { mengguna } \\
\text { kan teknik } \\
\text { Random } \\
\text { Club } \\
\text { dalam } \\
\text { kelas } \\
\text { speaking }\end{array}$ & $\begin{array}{c}\text { Variabe } \\
\text { I } \\
\text { depend } \\
\text { en }\end{array}$ \\
\hline
\end{tabular}

Note : $\quad \begin{array}{ll}\mathrm{R} & =\text { Penilaian secara } \\ & \text { acak } \\ \mathrm{X} 1 & =\text { Dengan Perlakuan } \\ \mathrm{X} 2 & =\text { Tanpa Perlakuan } \\ \mathrm{O} & =\text { Posttest }\end{array}$

Adapun beberapa prosedur yang harus dilakukan sebelum teknik ini diterapkan oleh peneliti. Penelitian ini menggunakan SPSS 16.0. untuk menentukan normalitas data. Dalam hal ini, Kolmogorov-Smirnov and Shapiro-Wilk digunakan.

Kriteria dari penyebaran data normal dapat dilihat sebagai berikut:

- Jika, $\mathrm{p}<0$, 05, penyebaran data tidak normal

- Jika, $\mathrm{p}>$ 0, 05, penyebaran data normal
Nilai mahasiswa dianalisa dengan menggunakan Levene Statistic. Nilai mahasiswa dianalisis dengan menggunakan SPSS 16.0. Jika nilai signifikansi lebih dari 0.05 , maka sampel yang digunakan homogen. Jika nilai signifikansi kurang dari 0.05 , maka sampel dikatakan tidak homogen.

Intrumen - instrumen yang digunakan dalam penelitian ini yaitu:

1. Rencana pembelajaran

2. Performance test (menggunakan gambar dan rubrik penelitian)

Performance test adalah tes yang digunakan untuk mengukur penampilan individu dalam kemampuan khusus. Dalam penelitian ini, peneliti menggunakan perfomance test untuk mengukur kemampuan berbicara mahasiswa.

Rencana pembelajaran adalah instrumen paling penting yang digunakan peneliti dalam melakukan penelitian ini. Tanpa instrumen ini peneliti tidak memiliki pedoman tentang bagaimana cara menerapkan teknik Random Club dalam penelitian ini.

Gambar-gambar yang digunakan dalam penelitian ini adalah gambar gambar makanan. Gambar tersebut digunakan untuk mempermudah siswa dalam menjelaskan makanan di situasi nyata.

Data yang diperoleh merupakan quantitatif data yang dijelaskan menggunakan dua tipe yaitu analisis statistik deskriptif dan analisis statistik inferensial. Analisis deskriptif memerlukan mean, median, modus, dan standar deviasi. Statistik inferensial diperoleh dengan menggunakan t-test.

Rumus t-test yaitu:

$$
\begin{aligned}
\mathbf{S}_{\mathbf{x}-\mathbf{y}} & =\frac{\sum(X-\bar{X})^{2}+\sum(Y-\bar{Y})^{2}}{n_{1}+n_{2}-2} \\
\mathbf{t} & =\frac{\bar{X}-\bar{Y}}{S x-y}
\end{aligned}
$$




\section{HASIL DAN PEMBAHASAN}

\section{A. Hasil}

$\mathrm{X}=$ Kelompok eksperimen

$\mathrm{Y}=$ Kelompok kontrol
a. Median
$: x=85.00$
b. Mode
$y=70.00$
$: \mathrm{x}=85.00$
c. Mean
$y=70.00$
d. Variance
$x=85.16$
e. Standard Dev.
$: x=4.76$
$y=20.96$
f. $\mathrm{t}$
$: x=2.18$
$y=4.57$
g. Ho ditolak and Ha diterima

\section{B. Pembahasan}

Sebelumnya ditemukan bahwa ada perbedaan antara nilai rata-rata dari kelompok eksperimen dan kelompok kontrol. Perbedaan tersebut dapat dilihat dari nilai signifikansi dari $t$-test yaitu .000 . Pernyataan ini juga didukung oleh $t$ cent (.05) tingkat signifikansi alpha. Jika nilai $t$ observed melebihi nilai $t$ critical 1.96, maka hipotesis nol ditolak. Dalam penelitian ini, $\mathrm{t}$ observed adalah 15.467 melebihi nilai $t$ critical 1.96, maka hipotesis yang menyatakan bahwa tidak terdapat perbedaan yang signifikan antara mahasiswa yang diajarkan dengan menggunakan teknik Random Club dengan mahasiswa yang diajarkan dengan teknik konvensional dalam kemampuan berbicara mereka ditolak.

\section{PENUTUP}

Dari hasil penjelasan di atas, peneliti dapat menyimpulkan bahwa terdapat perbedaan signifikan antara mahasiswa yang diajarkan dengan menggunakan teknik Random Club dan mahasiswa yang diajarkan dengan teknik konvensional. Berikut ini adalah beberapa saran yang ditujukan bagi dosen dan mahasiswa, yaitu: Untuk Dosen Bahasa Inggris Profesi

1. Mengetahui karakteristik masing-masing mahasiswa.

2. Mengganti teknik konvensional dalam mengajar speaking dengan teknik mengajar yang lebih efektif.
3. Memberikan banyak kesempatan mahasiswa berdiskusi dalam sebuah kelompok.

4. Memberikan informasi kepada peneliti baru mengenai hasil penelitian sebelumnya dalam menggunakan teknik Random Club.

5. Memberikan panduan kepada peneliti agar dapat memberikan hasil yang lebih baik terhadap kemampuan berbicara mahasiswa.

Untuk Mahasiwa

1. Belajar bersosialisasi antara mahasiswa yang satu dengan yang lainnya karena mereka tidak hanya mampu berinteraksi dengan teman dekatnya tetapi juga mereka mampu berinteraksi dengan semua mahasiswa yang ada di kelas. Jangan pernah takut dalam menggunakan Bahasa Inggris.

\section{DAFTAR PUSTAKA}

Cutting,Joan. 2000. The Grammar of Spoken English and EAP Teaching. Great Britain:University of Sunderland press

Dewi, Ida Ayu Putu Widya. 2006. The Effect of Intensive Dialogue on the First Year Students' Speaking Competency of SMA Negeri 3 Singaraja. Unpublished thesis: Universitas Pendidikan Ganesha

Hammer, Jeffrey C., Sokolof, Martin A. and Salisch, Sandra L. 2002. Speaking Clearly, Improving Voice and Diction. Sixth edition. New York: Mc. Graw.Hill

Nunan, David. 2003. Practical English Language Teaching. New York: The McGraw-Hill Companies, Inc

Wiersma, W. 1986. Research Methods in Education: An Introduction $4^{\text {th }}$ Edition. Toronto: Allyn \& Bacon, Inc. 